\title{
German research reactor gets local backing
}

Munich. Plans for the Technical University of Munich's controversial research reactor FRM-II, which will use highly enriched uranium to produce a high-energy neutron source for researchers, have been endorsed by the state government of Bavaria.

Last week, the state agreed to pay around DM300 million (US\$428 million) of the project's estimated cost of DM680 million, and approved Siemens as the main contractor. It also agreed to spend DM1.5 million on preparing the site of the reactor, due to be built at Garching near Munich; part of this cost will be for the construction of a fence to keep out objectors.

The consensus agreement, pushed through in the last session of the government's finance committee before the summer recess, has been heavily criticized by Germany's Social Democrat and Green parties, partly because of its uncertain finances and partly because of uncertainties over the source of the highly enriched uranium.

Financially, the agreement depends on the federal government agreeing to increase its promised contribution to the project, which was based on sharing equally the costs when they were estimated to be only DM525 million earlier this year.

This outcome is by no means guaranteed. Nor has it been agreed who will pay for any future cost rises in the project, which could rise to more than DM1 billion by the time the project is completed.

A more general concern is that FRM-II may end up as a high-cost white elephant, unable to obtain the fuel that it will need. In building the reactor, Germany would break ranks with other nations that are complying with a US initiative to convert research reactors to the use of low enriched uranium, whose threat of contributing to proliferation of nuclear weapons is perceived as being lower (see Nature 369, 89; 1994).

The United States controls the world's supply of highly enriched uranium for research reactors, and now supplies it only to reactors that cannot physically be converted to low enriched uranium. The Germans are unwilling to change the design of FRM-II because of the extra running costs involved.

The United States now seems unlikely to shift its position. In May, it sent a statement to the German government confirming that "the US would not supply any new foreign research reactor, such as the planned Garching reactor to be built at the University of Munich".

Klaus Böning, the physicist who heads the FRM-II project, says that the US stand is unfair as Germany, which is a signatory to the NuclearNon-Proliferation Treaty, would subject all its nuclear fuel to international scrutiny, and would therefore pose no threat.

Now, he says, Germany is depending on the European nuclear supply agency Euratom

to find a solution. Euratom is said to be looking at the United Kingdom, France and Russia as possible local suppliers of highly enriched uranium. Euratom is known already to have visited Moscow, accompanied by a representative from the FRM-II project in Garching as observer.

The outcome of these meetings is not known. But the United States has confirmed that it is also negotiating with the three countries involved to persuade them not to re-export highly enriched uranium originating in the United States.

Although the FRM-II has still to receive a nuclear licence, this is expected to be granted next year despite vociferous opposition. Given the political and financial problems that the reactor has generated, Bavaria's motives for pushing the project so hard are unclear, although one theory is that the building of the reactor will provide a major boost to local high-technology industries.

\section{Neutron sources need collaboration}

Paris. Better medium- and long-term planning of neutron sources is needed, according to a report submitted last week to the 'megascience' forum of the Organization for Economic Cooperation and Development (OECD) on synchrotron radiation sources and neutron beams.

In particular, many neutron sources in Europe are "too small, underfunded and underused", according to Peter Tindemans the chairman of the forum. The task, he says, is to find agreement on which sources should be closed, and on what timescale, and to arrange multilateral funding to concentrate resources on those remaining.

Pressure is growing for greater international cooperation in neutron beams and synchrotron radiation sources because of the growing costs of the machines - up to US $\$ 2$ billion - and the need for facilities to meet the varied requirements on small users from different disciplines.

Last week's meeting agreed that one model of cooperation is that developed among the three big third-generation synchrotrons, namely the European Synchrotron Radiation Facility (ESRF), the US Advanced Photon Source (APS) and the Japanese SPring-8.

This model could be applied to smaller neutron and synchrotron facilities, says the report. It also suggests that the United States and Europe should take the opportunity to coordinate from the outset the construction of the proposed US advanced neutron source (ANS) and the proposed European spallation source (ESS)

According to Tindemans, the United States has agreed to hold a joint conference
The FRM-II, designed by the Munichbased company Siemens, has a unique design described by Paul Leventhal, president of the US-based Nuclear Control Institute, at a public meeting in Munich last month, as "the sports car version of the research reactor". He added: "It is small, powerful and a viable export item"; that was why it was a "particularly dangerous" threat to US efforts to control the spread of enriched fuel.

Scientists have been continuing to take sides in the dispute. A protest letter signed by 50 German physicists and published at the end of May was followed two weeks later by a letter of support signed by more than 300 scientists.

While openly bullish on the outcome, Bavaria has been keeping its options open. In agreeing the project last week, the state government reserved its right to pull out of the agreement "if financial or technical changes are too serious". Alison Abbott with the OECD in November on nextgeneration spallation sources costing between US\$0.5 billion and US\$1 billion.

The forum also discussed the conclusions of an expert report on particle physics. The two main items on the particle physicists' shopping list are a high-energy hadron collider - of which the large hadron collider (LHC) is now the only one currently being planned - and subsequently a large electron-positron linear collider (known as the next linear collider, or NLC).

Tindemans says that the megascience forum is trying to persuade governments to make NLC an international project (participating institutions have produced a memorandum of understanding on joint research and development). $\mathrm{He}$ is concerned that otherwise the NLC may suffer the same fate as the Superconducting Super Collider (SSC), recently killed off in the US Congress (see Nature 365, 773; 1993).

He stresses the importance of scientists and politicians talking together and suggests, for example, that the membership of the International Committee for Future Accelerators should be enlarged, with government officials invited to participate more frequently than once every three years.

The megascience forum also discussed how best to ensure its own future, which is due to be decided at a ministerial meeting next year. The forum itself would like to be given responsibility for monitoring and catalysing international scientific collaboration, and more political clout through the increased participation of high-level government officials in its meetings.

Declan Butler 